\title{
Water Productivity in a Mediterranean Semi-Arid Greenhouse District
}

\author{
José Alberto Sánchez ${ }^{1}$ Juan Reca ${ }^{1} \cdot J_{u a n}$ Martínez $^{1}$
}

Received: 2 December 2014 / Accepted: 30 August 2015 /

Published online: 4 September 2015

(C) The Author(s) 2015. This article is published with open access at Springerlink.com

\begin{abstract}
An irrigation performance analysis has been carried out in a horticultural greenhouse area located in the "Campo de Nijar" (Southern Spain) in order to assess its irrigation productivity. Irrigation water productivity indicators were calculated for a wide sample of crops over the course of two different study periods. These productivity indices were similar in average to those reported in other nearby greenhouse irrigation districts although their variability was very high. The overall productivity ratio $(C Y R)$ was $73.9 \%$. The low values for $C Y R$ were expected as irrigation water in this area has high salinity levels and low irrigation leaching fractions were applied. The influence of type of crop, greenhouse technology and agricultural season in the $C Y R$ values was analyzed. None of these factors had a statistically significant influence. A multivariate regression analysis was performed to model the crop yield as a function of several quantitative variables. The results showed that the most significant variable was the relative irrigation supply $(R I S)$. Other variables that had an influence of the productivity were the length of the growing cycle in the case of tomato and the number of greenhouses per farm in the case of watermelon. Results of this work are useful as they highlight the weaknesses of the system and suggest possible measures in order to improve its productivity and sustainability.
\end{abstract}

Keywords Greenhouse · Irrigation districts · Irrigation management · Irrigation productivity · Salinity

\section{Introduction}

Agriculture is the largest water consumer in the world. More than two thirds of total water use is devoted to the irrigation of agricultural lands. The land area of greenhouses in the world

Juan Reca

jreca@ual.es

Juan Martínez

jumartin@ual.es

1 Department of Engineering, University of Almería, 04120 Almería, Spain 
exceeds 700,000 ha, mainly concentrated in Asia, in the Mediterranean Basin and in central and northern Europe.

Sustainability, in many productive irrigated areas, is threatened by the limited availability of water resources. This is the case of many irrigation areas that use groundwater resources (Clemens 2006; Ahmad et al. 2014), and more particularly, of greenhouse irrigation areas in the Mediterranean Basin.

Proper irrigation management is essential to improve crop production and irrigation productivity. However, many factors are involved in the efficient use of water, such as crop type, irrigation method, soil or substrate type, weather conditions, agricultural prices and markets, and farmers' management decisions, among others.

The concept of 'efficient use of water' applied to irrigation is complex and can be defined in different ways (Howell 2001). Classic irrigation efficiency concepts were defined in terms of a water balance in the different parts of an irrigation system: conveyance, distribution or application (Wolters 1992). However, Irrigation performance indices that take into account the productive or economic results of the water devoted to irrigation are increasingly gaining interest. This is the case of the water productivity lindex proposed by Perry (2007) The irrigation water productivity can be expressed either in terms of yield $\left(\mathrm{kg} / \mathrm{m}^{3}\right)$ or in terms of economic returns $\left(€ / \mathrm{m}^{3}\right)$ (Malano et al. 2004; Pande et al. 2012; Yihun et al. 2013; Martínez and Reca 2014).

Different sets of indicators have been proposed to evaluate the performance of irrigation systems (Bos et al. 1994). The use of these performance indicators together with benchmarking techniques and data envelopment analysis has proved to be a good tool for improving the water management in irrigation districts (Malano et al. 2004; Rodríguez et al. 2004; Córcoles et al. 2012; Ali and Klein 2014). Other recent studies have introduced the concept of "virtual water" and "water footprint" and have applied these concepts for water planning and allocation at a regional scale (Hoekstra and Chapagain 2007; Aldaya et al. 2010; Montesinos et al. 2011; Su et al. 2014)

The purpose of this study is to evaluate the irrigation water productivity in a greenhouse irrigation district in the southeast of Spain with increasing problems regarding the irrigation water availability and quality (The "Campo de Nijar" area). This research work tries to fill the gap of irrigation performance and productivity assessment studies in Mediterranean greenhouse districts as there are few previous studies regarding this issue. Perhaps, one of the most comprehensive and specific studies is that conducted by Fernández et al. (2007) in a nearby greenhouse area in southern Spain, although it was performed in an area with much less severe water scarcity and salinity problems.

A previous study was conducted by our research group in order to analyze the adequacy of the irrigation practices of the main greenhouse crops in this area (Sánchez et al. 2015). This study showed that the irrigation water supply was slightly greater than the crop net irrigation water requirements. The overall mean relative irrigation supply $(R I S)$ value, defined as the ratio of the total irrigation water applied over the net crop irrigation requirements, for all crops was 1.12. This value indicates that the crop water needs were satisfied on average. However, a high $R I S$ variability was observed. There were significant differences in the irrigation performance among farmers depending on their individual management decisions and irrigation skills.

Farmers in this area irrigate with water withdrawn from saline aquifers. The mean value of the electrical conductivity of the irrigation water was around $3.5 \mathrm{dS} / \mathrm{m}$ during the study period. The use of water with such a high salinity level is expected to reduce crop yields (Ayers and Westcot 1985) unless sufficient leaching fractions are applied. However, the results of the study by Sánchez et al. (2015) showed that the experimentally observed leaching fractions 
were lower than those expected to attain a maximum crop yield. On the other hand, the selection of relatively salt tolerant crops (like tomato and watermelon) and the use of drip irrigation systems may ease the effect of salinization on crop yield. In addition, farmers apply high efficiency pre-planting leaching irrigations and they usually prioritize improving taste and quality over achieving a maximum or potential yield, especially for crops like tomato.

For these reasons, in this paper, a performance evaluation study is going to be performed with the aim of assessing the farmers' irrigation water management and productivity. Appropriate irrigation water productivity indices are going to be calculated for a wide and representative sample of farms and crops in the area. A statistical methodology is going to be applied to explain the variability of the productivity indices and to assess the effect of the most significant factors conditioning the irrigation water management and productivity in this specific area. This study is very important to investigate how these variables could be improved with the aim of achieving not only a maximum productivity of the scarce irrigation water but also of contributing to save water, preserve the environment and reinforce the sustainability of the agricultural system

\section{Material and Methods}

\subsection{Description of the Study Area}

The Campo de Nijar Area, where this study was conducted, is located in the eastern part of the Province of Almería (Spain). It is the second most important greenhouse production area in this province with a total surface of 3850 ha of greenhouses, which represents $14 \%$ of the total province greenhouse area (Sanjuán 2007). Southeast Spain is one of the most arid regions in Europe. It has a semi-arid Mediterranean climate, characterized by mild winter temperatures ( $18^{\circ} \mathrm{C}$ annual average temperature), high solar radiation (from 3000 to 3600 sunlight hours per year) and scarce and variable precipitations with an average annual rainfall lower than $300 \mathrm{~mm}$ per year.

Greenhouses are built with a light structure and covered with a plastic film. In this area, two groups of greenhouse can be distinguished: low and medium technology greenhouses. The typical soil in this area is an artificial layered soil called 'enarenado', which utilizes a thin layer of sand on the top (Fernández et al. 2007).

Water resources are very limited in the area, especially surface water resources. The increasing withdrawals of irrigation water from the aquifer system are causing severe overexploitation and a drop in groundwater levels. In addition to the water resources shortage, there are also serious concerns regarding the quality of the irrigation water in the area. An increasing salinisation of the aquifer is taking place due to the saline irrigation return flows (Thompson et al. 2007). The average electrical conductivity in the irrigation district where this study was conducted was approximately $3.5 \mathrm{dS} / \mathrm{m}$.

This research is focused on the "SAT N ${ }^{\circ}$. 2130. Campo de Nijar" irrigation district. It is the widest irrigation district in the area and supplies water to a total of 690 farmers and 1334 ha. Water is stored in three regulating reservoirs with a total storage capacity of $250,000 \mathrm{~m}^{3}$ and is distributed to the farmers through a pressurized, on-demand, looped pipeline network. The water distribution system is fed with water withdrawn from the "Campo de Nijar" aquifer through a total of 15 wells with dynamic ground water levels at a depth exceeding $100 \mathrm{~m}$. As a result, the cost of pumping water is high in this area (Reca et al. 2014). 
Drip irrigation is the main irrigation method used in greenhouses. Farmers usually have water ponds in order to guarantee water availability. From there, the water is pumped into the on-farm irrigation distribution system.

\subsection{Crops}

The horticultural crops in this area are limited to the crops most tolerant to salinity, such as tomato and watermelon. Tomato is the most widespread crop (55\% of the total area). The second one is watermelon (20\%), followed by cherry tomato (16\%) (Valera et al. 2014). In this study, we have focused on these three crops: tomato, watermelon and cherry tomato as they represent more than $90 \%$ of the area.

\subsubsection{Tomato}

There are different varieties of tomato in the area: long-life, pear, cluster, etc. Planting dates ranges from late July-August (early cycles) to late August-September (late cycles), although crops are usually planted during August. Two different types of growing cycles can be distinguished depending on their length: short cycles (5-6 months) and long cycles (1011 months). The most commonly used planting density is 2 plants $/ \mathrm{m}^{2}(0.5 \times 1)$. We have focused our study on autumn short-cycle pear tomatoes.

\subsubsection{Cherry Tomato}

The main difference between tomato and cherry tomato lies in their planting densities. Plant separation is shorter than in other tomato varieties. The planting densities range from 2.5 to 4 plants $/ \mathrm{m}^{2}$. However, cherry tomato plants have more than 1 stem (between 2 and 3 on average), so the planting density is higher if the number of stems per square meter is considered.

\subsubsection{Watermelon}

Watermelon crops are more homogeneous than those of tomato. They are exclusively spring cycle crops. However, planting dates range from late December-January (early cycles) until March or April (late cycles). The duration of the growing cycle ranges from 3.5 to 4 months depending on the plantation date and growing conditions. Plant density is considerably lower than tomato. The most usual layout is $1 \mathrm{~m} \times 4 \mathrm{~m}\left(0.25\right.$ plants $\left./ \mathrm{m}^{2}\right)$.

Agricultural season in this area is considered to begin on August 1st (when the autumn cycles begin) and it lasts until July 31th of the next year. The typical crop rotation is composed of two crops per year: tomato (autumn cycle) - watermelon (spring cycle), tomato (autumn cycle) - tomato (spring cycle). Nevertheless, some farmers choose to grow one long tomato cycle.

\subsection{Experimental Set-Up}

In order to evaluate irrigation productivity, its possible evolution over time, and the most important limiting factors contributing to the irrigation productivity achieved in this area, two different study periods were considered: 


\subsubsection{First Study Period (2005/06 to 2008/09 Agricultural Seasons)}

This first period includes four consecutive agricultural seasons for which overall statistical data on irrigation water consumptions and yields were collected for a wide sample of farms. With the aim of being representative of the whole area, farms with different technology levels and types of crop were selected.

The sample was composed of a total of 125 different plots. The area covered by this sample was $119.54 \mathrm{ha}$. A total of 34 out of these 125 plots were pear tomato ( $24.31 \mathrm{ha}), 38$ were cherry tomato (44.73 ha) and 53 were watermelon ( $50.50 \mathrm{ha}$ ). The temporal distribution of the sample was 28, 32, 38 and 27 plots in each season from 2005/06 to 2008/09, respectively.

Cropping data records were collected for the study period for the selected sample of farms. These data include crop distribution, planting and harvesting dates for each crop and cropping techniques. These data were provided by the main commercialization cooperative in the area and were also gathered from surveys of farmers and agronomists.

The irrigation water used by farmers during this period came only from the aquifer and was supplied by the "SAT n 2130 Campo de Nijar" irrigation distribution network. Data on irrigation water consumption for each farm were provided by this irrigation water supply institution. Data were obtained from the readings of the water meters installed in the hydrants of the water distribution network. The contribution of rainfall water can be considered negligible and no desalinated water was available during this period. Marketable yields and the prices of the products for the data sample were provided by the main commercialization cooperative in the area.

\subsubsection{Second Study Period (2011/12 to 2012/13 Agricultural Seasons)}

In the second period comprising two agricultural seasons, an in-depth field survey was carried out for a reduced sample of farms (12 plots). The irrigation water balance and the most important crop and yield variables were monitored on a daily basis for the whole irrigation season of each crop in this reduced sample. The aim of this study was to review the results obtained in the previous period and analyze the possible changes in the irrigation water management and productivity.

The amount of irrigation water applied was measured daily from the data provided by the on-farm drip irrigation system controller. The electrical conductivity of the irrigation water discharged by the emitters was measured weekly. In this second period, irrigation water quality was slightly improved by using desalinated water supplied by the Carboneras desalination plant mixed with the brackish water withdrawn from the aquifer. Marketable yields and the prices of the harvest were provided by the main commercialization cooperative in the area.

\subsection{Crop Water Requirements Calculation}

The crop evapotranspiration $\left(E T_{c}\right)$ was calculated by the model developed by Orgaz et al. (2005), which is locally calibrated and adapted to the greenhouse climatic conditions. It follows the methodology proposed by the Food and Agriculture Organisation of the United Nations (FAO) (Allen et al. 1998), based on separately considering the effects of climate (reference evapotranspiration, $E T_{o}$ ) and plant canopy (crop coefficient, $K_{c}$ ) on crop water consumption. 


$$
E T_{c}=E T_{o} \cdot K_{c}
$$

In order to calculate $E T_{o}$, an adjusted FAO-Radiation equation proposed by Bonachela et al. (2006) has been used.

The $K_{c}$ values for horticultural crops grown under greenhouse climatic conditions in Southern Spain were calculated following the methodology proposed by Orgaz et al. (2005) and Bonachela et al. (2006).

In order to consider the variability in the study area among farms and crops, in this work, the crop water needs are going to be calculated for every individual plot in the studied sample as a function of its growing cycle and type of greenhouse.

For the first period, indoor climate data for every single greenhouse were not available. To overcome this limitation, these data were derived from outdoor climate measurements taken from the Nijar agroclimatic station belonging to the network of agroclimatic stations of the Government of Andalusia (Spain). Regressions equations for all the required climate variables (radiation and temperature) for every specific type of greenhouse and crop cycle were performed (Sánchez et al. 2015).

For the second period, required climate variables were measured inside every greenhouse using HOBO U30 weather stations, with temperature, relative humidity and radiation sensors.

Outdoor climate data for both study periods are shown in Table 1 . The higher variability among agricultural seasons was experienced in the annual rainfall (C.V equal to $20 \%$ ). However, the coefficient of variation of the outdoor reference evapotranspiration was equal to $5 \%$.

\subsection{Productivity Indices}

With the aim of analyzing the water productivity, several productivity indices have been used in this study. The values of these indices have been calculated for the greenhouse data sample described in the previous section. The set of indicators selected is the following (Molden and Sakthivadivel 1999):

- Crop Water Productivity $\left(C W P, \mathrm{~kg} / \mathrm{m}^{3}\right)$ is defined as the ratio between the marketable crop yield $\left(\mathrm{kg} \cdot \mathrm{m}^{-2}\right)$ and the irrigation water supply to the crop (IWS, $\left.\mathrm{m}^{3} / \mathrm{m}^{2}\right) . C W P$ is a relevant irrigation performance indicator, especially for areas with limited water (Howell 2001)

Table 1 Outdoor climate data for both study periods

\begin{tabular}{lllllllr}
\hline Season & $\begin{array}{l}\text { T. Max } \\
\left({ }^{\circ} \mathrm{C}\right)\end{array}$ & $\begin{array}{l}\text { T. Min } \\
\left({ }^{\circ} \mathrm{C}\right)\end{array}$ & $\begin{array}{l}\text { T. Mean } \\
\left({ }^{\circ} \mathrm{C}\right)\end{array}$ & $\begin{array}{l}\text { Wind speed } \\
(\mathrm{m} / \mathrm{s})\end{array}$ & $\begin{array}{l}\text { Radiation } \\
\left(\mathrm{MJ} / \mathrm{m}^{2} / \text { day }\right)\end{array}$ & $\begin{array}{l}\text { Rainfall } \\
(\mathrm{mm} / \text { year })\end{array}$ & $\begin{array}{l}\text { ETo } \\
(\mathrm{mm} / \text { year })\end{array}$ \\
\hline $2005 / 06$ & 23.1 & 13.4 & 18.1 & 1.84 & 17.2 & 255.6 & 1358.8 \\
$2006 / 07$ & 23.4 & 13.4 & 18.2 & 1.76 & 17.7 & 164.6 & 1233.2 \\
$2007 / 08$ & 22.8 & 13.4 & 17.9 & 1.90 & 18.1 & 246.4 & 1358.7 \\
$2008 / 09$ & 22.5 & 12.9 & 17.5 & 1.90 & 18.2 & 242.4 & 1366.6 \\
$2011 / 12$ & 23.6 & 13.1 & 18.2 & 1.77 & 19.0 & 159.0 & 1415.1 \\
$2012 / 13$ & 23.2 & 12.8 & 17.7 & 1.77 & 18.8 & 203.6 & 1328.8 \\
Averag. & 23.1 & 13.2 & 17.9 & 1.82 & 18.2 & 211.9 & 1343.5 \\
Max. & 23.6 & 13.4 & 18.2 & 1.90 & 19.0 & 255.6 & 1415.1 \\
Min. & 22.5 & 12.8 & 17.5 & 1.76 & 17.2 & 159.0 & 1233.2 \\
C.V. & $1.7 \%$ & $2.3 \%$ & $1.5 \%$ & $3.5 \%$ & $3.5 \%$ & $20.2 \%$ & $4.5 \%$ \\
\hline
\end{tabular}


- Economic Water Productivity $\left(E W P, € / \mathrm{m}^{3}\right)$ : is defined as the ratio between economic return produced by the crop $\left(€ / \mathrm{m}^{2}\right)$ and the irrigation water supply (IWS, $\mathrm{m}^{3} / \mathrm{m}^{2}$ ).

- Productivity index (Bos et al. 1994) (CYR) is defined as the ratio between the crop yield attained in actual conditions $\left(\mathrm{kg} / \mathrm{m}^{2}\right)$ and a reference yield that could be attained under appropriate water supply and management for local crop growing conditions $\left(\mathrm{kg} / \mathrm{m}^{2}\right)$. This dimensionless index has the advantage of making it possible to compare productivity levels among different crops.

\subsection{Assessment of the Reference Yield of the Crops}

In order to estimate the productivity index $(C Y R)$, it is necessary to assess a reference yield for each crop. This assessment is quite complex as potential yields depend on many factors: local climatic conditions under plastic greenhouses, soil type, irrigation and cropping management techniques, etc.

One of the first approaches to estimate the crop yield response to water was that proposed by Doorenbos and Kassam (1979). Different procedures for estimating potential yields are recommended in this paper, either from available local data for maximum crop yields or based on the calculation of maximum biomass and a corresponding harvest index. The recent advances in agronomy and crop physiology allow for the use of increasingly precise methods to estimate maximum yields. For example, the Aquacrop model can be used to calculate these variables (Steduto et al. 2012). However, this procedure requires a local calibration of the model parameters.

For this reason, we preferred to estimate these reference potential yield values from the broad sample of marketable yield data available for the three types of crops studied during the first period of study. A statistical analysis was performed to test whether these three samples of data fitted to different commonly used statistical distribution functions. The Weibull distribution was found to be the most appropriate statistical function. The potential reference yield adopted in this work was the yield value with a probability of being exceeded less than $1 \%$. This reference potential yield cannot be considered an absolute maximum yield value but a reasonable reference yield that could be attained provided the irrigation water applied and the crop management conditions are appropriate.

\subsection{Statistical Analysis}

Two different statistical analyses were performed in this work. A multifactor analysis of variance was carried out with the aim of evaluating factors that may influence the productivity of irrigation water. In this analysis, the productivity index was taken as independent variable and three possible factors were considered: type of crop, type of greenhouse and the cropping season. The crop type was used in order to detect possible differences in the irrigation management among crops. The type of greenhouse is associated with its technological level, and the agricultural season encompasses the climatic variability.

In addition, a multivariate regression analysis has been performed to model the yield of the crop as a function the irrigation water supply $(R I S)$ and other possible quantitative predictor variables such as the length of the growing cycle of the crop, the planting date and the size of the farm. A stepwise regression procedure was used to select the most significant dependent variables. Stepwise regression is a selection technique that makes it possible to differentiate the 
variables that really have a significant effect on the crop yield from the proposed set of possible independent or predictive variables.

All the statistical analyses in this work were performed with the Statgraphics statistical package (Statgraphics 2010).

\section{Results and Discussion}

\subsection{Reference Crop Yield}

The results showed a good agreement of the crop yield data sample to a Weibull distribution function for the three crops analyzed with $90 \%$ or higher confidence. ( $P$-values greater than 0.10 ),

The Weibull cumulative distribution function is given in Eq. 2 and it depends on two parameters: $\alpha$, the shape parameter of the distribution, and $\beta$ called the scale parameter.

$$
F(X)=1-e^{-\left(\frac{x}{\beta}\right)^{\alpha}}
$$

Figure 1 depicts the experimental data and the fitted Weibull function for the three crops. The shape and scale parameters of the distribution for each crop and the resulting reference yields are also illustrated in this figure.

The reference yields for pear tomato, cherry tomato and watermelon were $8.85 \mathrm{~kg} / \mathrm{m}^{2}$, $6.20 \mathrm{~kg} / \mathrm{m}^{2}$ and $6.85 \mathrm{~kg} / \mathrm{m}^{2}$, respectively. The comparison of these values with other similar greenhouse areas is not easy as yields data available in the literature are scarce and refer mostly to average values rather than potential ones. These values are lower than those that can be attained in other similar greenhouse areas with a better irrigation water quality and a more precise climate control. For example, Valera et al. (2014) reported a potential yield for a tomato grown in a Venlo type greenhouse in The Netherlands equal to $56.5 \mathrm{~kg} / \mathrm{m}^{2}$, considerably higher than the potential yields in Mediterranean greenhouses. These authors found an average

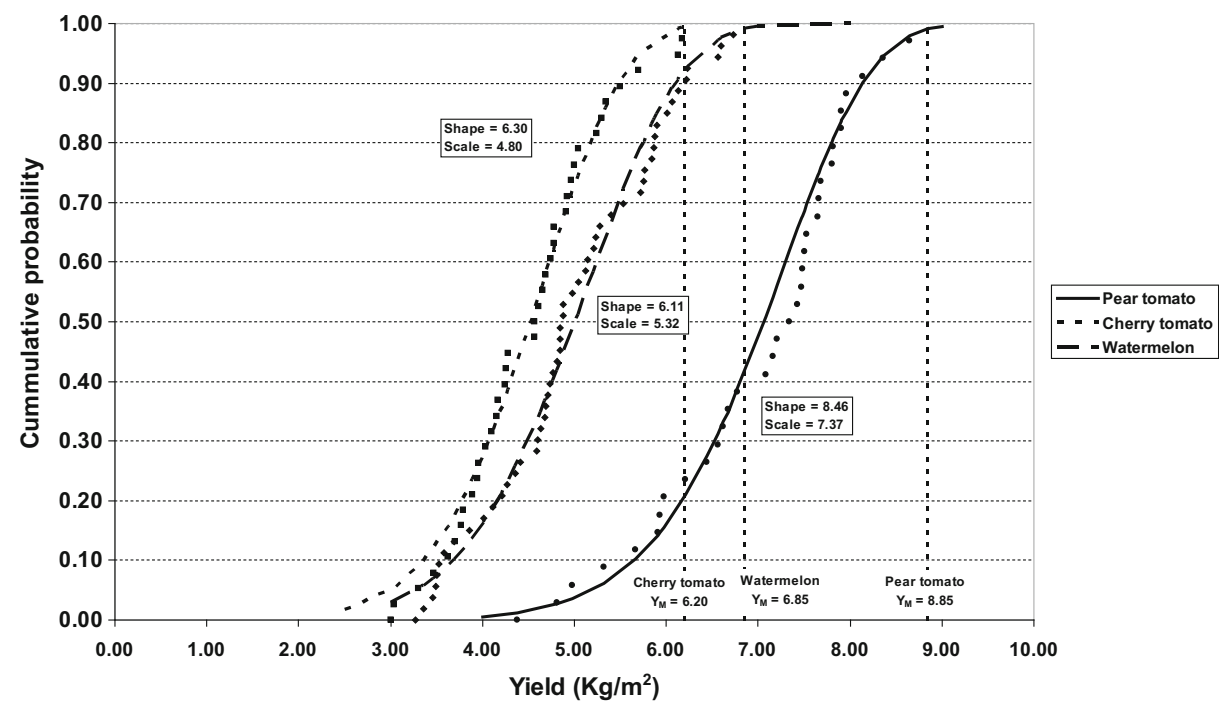

Fig. 1 Experimental yield data and fitted Weibull functions for the three crops 
yield for an autumn cycle tomato crop in the study area equal to $8.72 \mathrm{~kg} / \mathrm{m}^{2}$, close to yield found in this work, whereas the average tomato yield in the Campo de Dalías area (close to the study area but with slightly better quality and climate conditions) reaches $10.56 \mathrm{~kg} / \mathrm{m}^{2}$. Fernández et al. (2007) found an average yield for watermelon equal to $6 \mathrm{~kg} / \mathrm{m}^{2}$ in the Campo de Dalías area, slightly higher than the average yield obtained in this study (around $5 \mathrm{~kg} / \mathrm{m}^{2}$ ).

Reference yield values must be locally calibrated so they take into account local growing conditions. However, if local growing conditions change, potential yield values may also vary. It is important to point out that the watermelon yields increased in the second study period with respect to those obtained in the first period. The average yield during the second period was $6.6 \mathrm{~kg} / \mathrm{m}^{2}$. This increase can be attributed to the improvement of the irrigation water quality caused by the mixing of the water withdrawn from the aquifer with desalinated water provided by the Carboneras desalination plant. The average water salinity supplied to the farmers during the first study period was around $3.5 \mathrm{dS} / \mathrm{m}$ (the salinity increase due to fertigation is not included in this value) whereas the irrigation water quality obtained in the second period from the water sampling taken from the dripper discharge was around $3.0 \mathrm{dS} / \mathrm{m}$ (with fertigation included). The tomato yields did not change significantly in the second period as the farmers tended to prioritize fruit quality over quantity and the irrigation water salinity applied to the tomato crops did not vary substantially from that applied in the first study period $(3.5 \mathrm{dS} / \mathrm{m}$ in average for the tomato crops).

\subsection{Overall Productivity and Limiting Factor Analysis}

The average productivity ratio for all the crops was $73.9 \%$, with a coefficient of variation of $17.5 \%$. This result was expected considering the variability of the RIS values. It is important to point out that less than only $10 \%$ of crop cycles achieved a productivity index greater than $90 \%$. These limited crop yields are consistent with the poor quality of the irrigation water and the relatively low leaching fractions applied.

With the aim of analyzing possible factors contributing to the high variability of the $C Y R$ values, a multifactor analysis of variance was performed. The effect of three potential factors was considered: crop type, type of greenhouse and agricultural season. None of the three factors, nor their interactions, had a statistically significant effect on $C Y R$ at the $95.0 \%$ confidence level as the $P$-values were greater than 0.05 in all cases. However, the result of the mean comparison procedure showed that that pear tomato was significantly more productive than the other two crops at the $95.0 \%$ confidence level. The method used to discriminate among the means was the Fisher's least significant difference (LSD) procedure. Cherry tomato was less productive than pear tomato with similar RIS value. Watermelon was also less productive but its RIS value was higher. This shows that the watermelon crop was more sensitive to the water and salinity stress.

There were no significant differences in $C Y R$ values between low and high technology greenhouses.

\subsection{Single Crop Productivity Analysis}

Table 2 summarizes the mean values of the irrigation water supply (IWS), relative irrigation supply $(R I S)$, marketable yield $(M Y)$ and the productivity performance indices (CWP, EWP and $C Y R$ ) for the three crops analyzed during both study periods. 
Table 2 Performance indicators for all the crops

\begin{tabular}{|c|c|c|c|c|c|c|}
\hline \multirow[t]{2}{*}{ Performance index } & \multirow[t]{2}{*}{ Stats. } & \multicolumn{3}{|l|}{ 2005-2009 } & \multicolumn{2}{|l|}{ 2011-13 } \\
\hline & & Pear tomato & Cherry tomato & Watermelon & Pear tomato & Watermelon \\
\hline \multirow[t]{3}{*}{ IWS (mm) } & Averag. & 326 & 339 & 226 & 369 & 221 \\
\hline & Median & 313 & 333 & 220 & 360 & 208 \\
\hline & C.V $(\%)$ & 24 & 22 & 26 & 13 & 15 \\
\hline \multirow[t]{3}{*}{ RIS } & Averag. & 1.07 & 1.13 & 1.16 & 1.05 & 1.01 \\
\hline & Median & 1.04 & 1.1 & 1.15 & 1.04 & 0.99 \\
\hline & C.V (\%) & 23 & 25 & 30 & 7 & 25 \\
\hline \multirow[t]{3}{*}{ MY $\left(\mathrm{kg} / \mathrm{m}^{2}\right)$} & Averag. & 6.94 & 4.48 & 4.94 & 6.82 & 6.60 \\
\hline & Median & 7.27 & 4.57 & 4.85 & 6.71 & 6.3 \\
\hline & C.V (\%) & 15 & 17 & 19 & 8 & 10 \\
\hline \multirow[t]{3}{*}{ CWP $\left(\mathrm{kg} / \mathrm{m}^{3}\right)$} & Averag. & 21.85 & 13.68 & 23.05 & 18.74 & 30.56 \\
\hline & Median & 21.55 & 13.51 & 22.83 & 18.87 & 30.86 \\
\hline & C.V (\%) & 16 & 22 & 26 & 14 & 20 \\
\hline \multirow[t]{3}{*}{$\operatorname{EWP}\left(€ / \mathrm{m}^{3}\right)$} & Averag. & 9.4 & 14.92 & 8.07 & 7.76 & 10.64 \\
\hline & Median & 9.27 & 14.73 & 7.99 & 7.39 & 9.57 \\
\hline & C.V (\%) & 16 & 22 & 26 & 24 & 26 \\
\hline \multirow[t]{3}{*}{ CYR } & Averag. & 0.78 & 0.72 & 0.73 & 0.77 & 0.96 \\
\hline & Median & 0.82 & 0.74 & 0.72 & 0.76 & 0.92 \\
\hline & C.V $(\%)$ & 15 & 17 & 19 & 24 & 10 \\
\hline
\end{tabular}

Average RIS values were slightly higher than the unity in all the crops. The average RIS values fulfill the net crop irrigation water needs and to provide an additional amount of water for leaching. However, these leaching fractions seem to be insufficient to achieve yields close to the reference yields values in most of the cases. Watermelon was the crop with a higher average RIS value (1.16) whereas pear tomato had the lower (1.07) in the first study period. In the second study period, $R I S$ values for tomato were similar to those found in the first period whereas the RIS values for watermelon decreased close to the unity.

The average $M Y$ of the pear type tomato cycles analyzed was about $7 \mathrm{~kg} / \mathrm{m}^{2}$ and near $5 \mathrm{~kg} /$ $\mathrm{m}^{2}$ in the case of cherry tomato and watermelon. These values are slightly lower than the average values obtained in similar nearby areas. The improvement of the water quality has increased the $M Y$ values of the watermelon in the second period.

The highest average $C W P$ value was achieved by watermelon crops $\left(23 \mathrm{~kg} / \mathrm{m}^{3}\right)$, although pear tomato reached similar values (approximately $22 \mathrm{~kg} / \mathrm{m}^{3}$ ). The lowest average $C W P$ value was obtained by cherry tomato $\left(13.6 \mathrm{~kg} / \mathrm{m}^{3}\right)$. The crops showed fairly good average $C W P$ values, although in general, vegetables grown under greenhouses usually have higher water productivities than those grown outdoors. In the case of pear tomato, Carreño et al. (2000) found values ranging between 21 and $23 \mathrm{~kg} / \mathrm{m}^{3}$. However, Fernández et al. (2007) found a higher $C W P$ value for the watermelon grown in the Campo de Dalías area $\left(35.6 \mathrm{~kg} / \mathrm{m}^{3}\right)$. It is important to highlight the significant increase of the $C W P$ for the watermelon in the second study period.

The higher EWP value was obtained for cherry tomato $\left(14.9 € / \mathrm{m}^{3}\right)$ due to its higher price, followed by pear tomato $\left(9.4 € / \mathrm{m}^{3}\right)$ and the last one was watermelon $\left(8 € / \mathrm{m}^{3}\right)$. However, in the second period, the productivity of the watermelon $\left(10.64 € / \mathrm{m}^{3}\right)$ surpassed that of the pear tomato. Carreño et al. (2000) reported a value of $8.8 € / \mathrm{m}^{3}$ for tomato crops in this area. 
With respect to the $C Y R$, the maximum average value was obtained for pear tomato with a value of 0.78 while the lowest was found for cherry tomato (0.72). In the second study period, $C Y R$ values for each crop were calculated considering the reference potential yield estimated for the first period. However, as the crop yields increased in the case of the sample of watermelon crops, the $C Y R$ values calculated were significantly higher. Average $C Y R$ value was 0.96 and there were several crops with $C Y R$ values greater than the unity. The $C Y R$ value for tomato did not change in the second period while the watermelon increased in the second

The histograms of the CWP and $M Y$ for the first study period depicted in Fig. 2 show the significant differences in the values of these variables among farmers.

As the productivity index values are relatively low in many plots, further improvements in the irrigation water management and in the irrigation water quality might very well be needed in order to maximize the crop yield and productivity.

\subsection{Relationship Between Productivity and Irrigation}

Figure 3 shows the relationship between RIS and CWP and between RIS and the marketable yields $(M Y)$ for all the studied crops during the first study period.

Experimental data for both variables fitted well to second degree polynomial functions for all the crops (P-value less than $5 \%$ in all cases). In the case of pear tomato, the coefficient of determination between $M Y$ and RIS was 0.69 . It can be concluded that there is a clear relationship between both variables as the irrigation water applied explains $69 \%$ of the marketable yield variability for pear tomato crops in this area. Marketable yield increases as $R I S$ does until a maximum is achieved. This maximum yield occurs for RIS values of 1.45 according to the fitted curve. $M Y$ decreases for $R I S$ values exceeding this value. The leaching fraction $(L F)$ can be estimated as a function of RIS by means of Eq. 3.

$$
L F=\frac{R I S-1}{R I S}
$$

This result indicates that maximum $M Y$ values were achieved for an average leaching fraction approximately equal to $31 \%$. This is consistent with the salinity of the irrigation water applied, considering that tomato is moderately sensitive to salinity and the irrigation water salinity threshold for long-term use on sandy soils is about $3.5 \mathrm{dS} / \mathrm{m}$ (Steduto et al. 2012).

In the case of cherry tomato, the coefficient of determination was 0.5 for the RIS-CWP relationship. There is also a clear relationship between RIS and MY, although in this case data show a greater variability than that observed in the case of pear tomato. Here, the maximum $M Y$ values occur for $R I S$ values close to 1.30 (23\% leaching fraction on average).

For watermelon, a coefficient of determination was also close to 0.5 . The $M Y$ reaches a maximum RIS value of 1.30 for the fitted curve ( $23 \%$ leaching fraction). After this maximum value, the $M Y$ values decrease with increasing $R I S$ values.

Regarding the RIS-CWP relationship, the fitted curve has a maximum for a $R I S$ value of 0.75 in the case of pear tomato and 0.8 for cherry tomato. However, for these RIS values, the expected yields would be equal to $5.6 \mathrm{~kg} / \mathrm{m}^{2}$ for pear tomato and $5.9 \mathrm{~kg} / \mathrm{m}^{2}$ for cherry tomato. Both yield values are quite lower than the maximum attainable yield for these crops. For RIS values higher than the aforementioned maximum RIS the CWP values decrease indicating that the marginal profitability of the applied water becomes lower. For watermelon, the $C W P$ showed a continuous decreasing trend for all RIS values. 


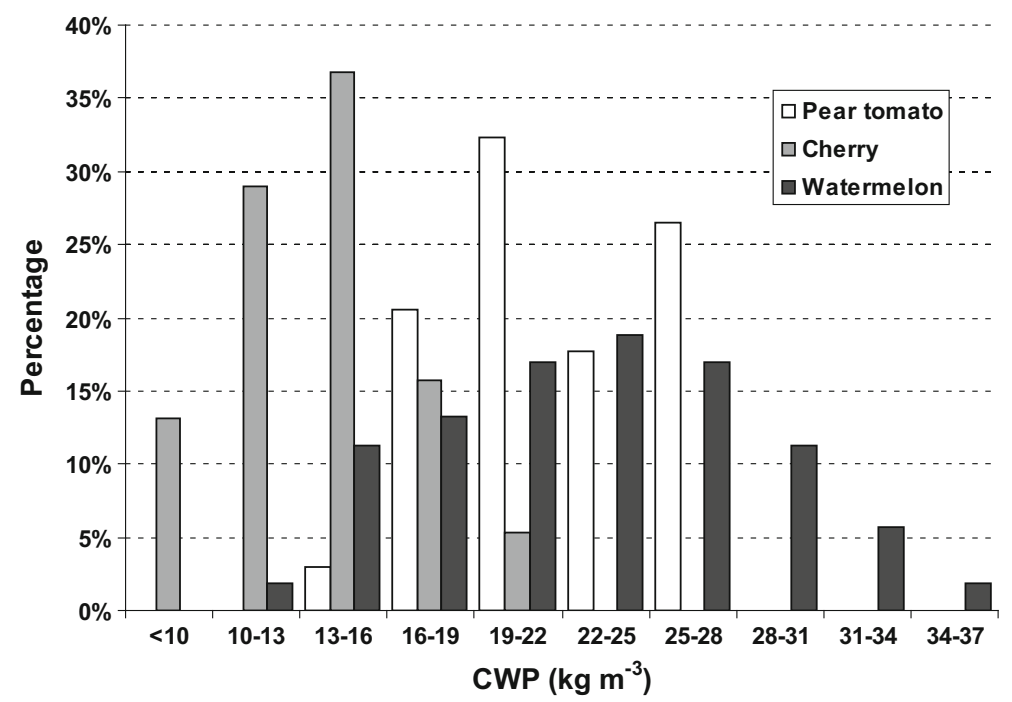

(a)

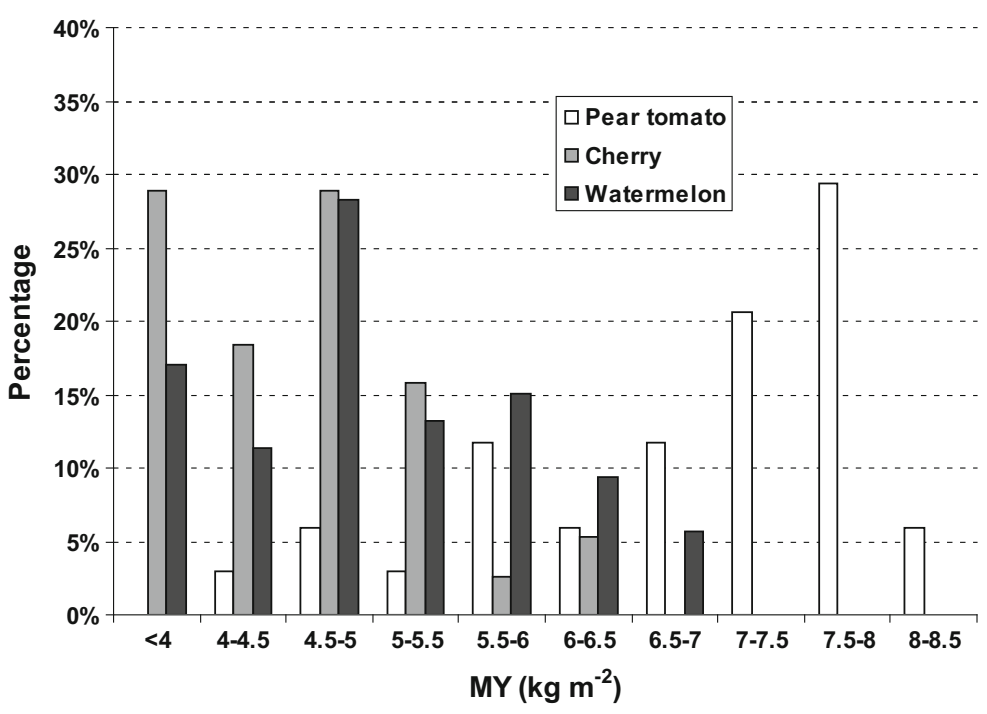

(b)

Fig. 2 Histograms of the CWP (a) and $M Y(\mathbf{b})$ values for all the studied crops in the Campo de Nijar area for the first study period (2005-2009)

The relationships found between the $M Y$ and the RIS for the studied crops show that the $M Y$ is highly related to the RIS. However, there is still a relatively high variability of the $M Y$ that remains unexplained. With the aim of explaining this $M Y$ variability more in depth, a multivariate regression analysis has been performed to model the $M Y$ as a function of other possible predictor variables. The following variables have been considered in this study: the relative irrigation water supply (RIS), the length of the growing cycle of the crop (GCL) as the larger the growing cycle the greater number of harvests in tomato (although not in 


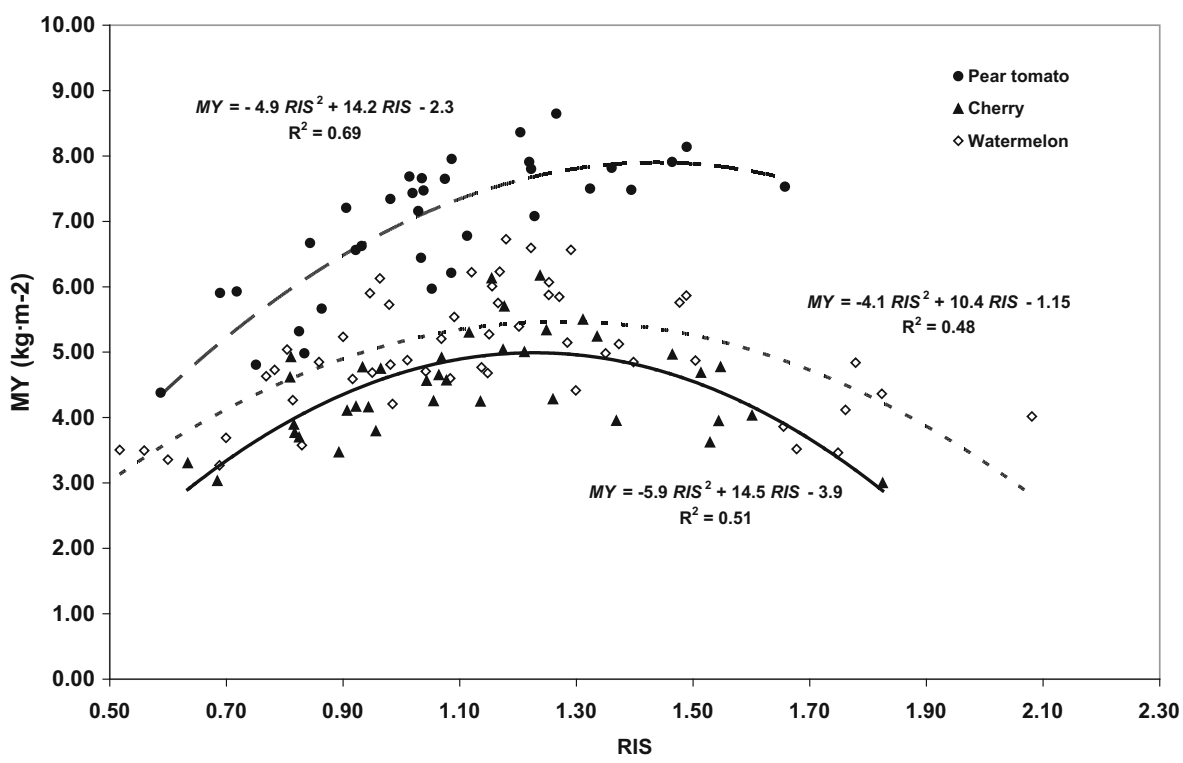

(a)

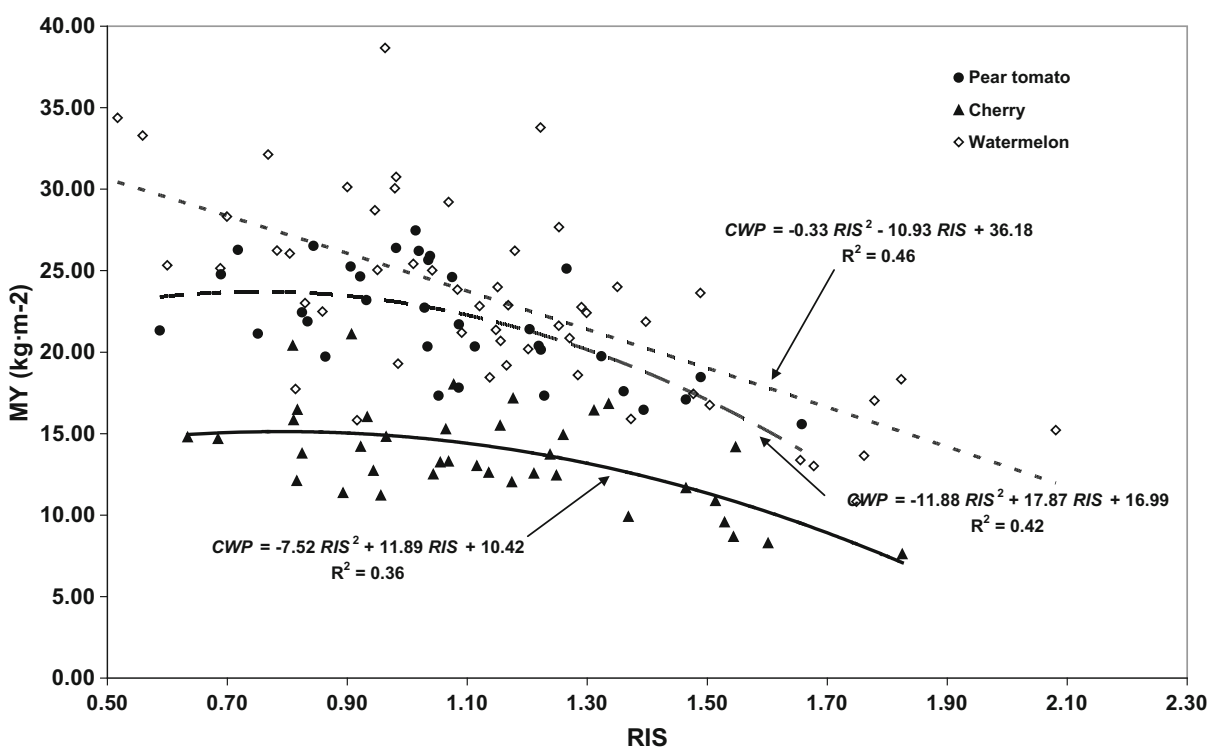

(b)

Fig. 3 RIS-MY (a) and RIS-CWP (b) relationships for all the crops (first period)

watermelon), the planting date $(P D)$ as it may affect the development of the crop, and farm area $(F A)$ and number of greenhouses of the farm $(N G)$ as both are related to the size of the farm and, indirectly, they are likely related to the technological level of the farmer and the training of the workers.

A stepwise regression procedure was used to select the most significant independent variables. At each step of the stepwise procedure, a new variable is entered or removed from 
the model based on the values of the partial F-test (F-value to enter or remove were equal to 4). The regressions coefficients and the independent variables selected by the stepwise regression procedure are shown in Table 3, along with the values of the goodness of fit statistics.

The stepwise analysis showed that the length of the growing cycle was also a significant predictor variable along with the quadratic relationship between $M Y$ and RIS. If this variable is added, the variability explained by the model increases from 69 to $75 \%$. The rest of variables considered in the analysis were not significant according to the stepwise procedure. These results can be explained taking into account that tomato fruits are harvested several times, so the larger the length of the cycle, the more likely that the number of harvests increases and thus the greater the yield is. Similar behaviour would be expected for the cherry tomato. However, in this case, neither the length of the growing cycle nor any other independent variables except the RIS resulted significant according to the stepwise regression procedure. The statistical variabilility of the $M Y$ explained in the case of the cherry tomato is considerably lower than in the pear tomato $(51 \%)$.

For watermelon crops, it is usual that the fruits are picked up only once, so the length of the growing cycle is not expected to be a significant variable. The stepwise regression has included the number of greenhouses of the farm as a significant predictor variable in this case. The variability explained by the model is equal to $55 \%$.

The variability that remains unexplained can be due to other factors that could not be considered in this study. One significant variable may be the salinity of the irrigation water supplied to every individual farmer. However, distributed values of salinity were not available in this study.

The distribution uniformity of the applied water does not seem a significant factor to explain the variability. On-farm irrigation performance evaluations for a sample of irrigation systems were carried out by the authors in a previous research work (Sánchez et al. 2015) and the irrigation uniformity was high in the majority of on-farm drip irrigation systems. The resulting average value of the Statistical Uniformity (US) (Bralts and Edwards 1986) was 0.91 with a coefficient of variation equal to $5 \%$.

Other factors that may contribute to the variability and that have not been included in this analysis are: the different crop varieties of crop with different performance and adaptation to the greenhouse environmental conditions, physical, chemical and pathological characteristics

Table 3 Multivariate stepwise regression results

\begin{tabular}{|c|c|c|c|c|}
\hline & Parameter & Pear tomato & Cherry tomato & Watermelon \\
\hline \multirow{7}{*}{$\begin{array}{l}\text { Regression } \\
\text { coefficients }\end{array}$} & $R I S$ & $13.2055( \pm 2.9071)$ & $14.535( \pm 2.4229)$ & $8.3567( \pm 1.6189)$ \\
\hline & $R I S^{2}$ & $-4.4807( \pm 1.3035)$ & $-5.9183( \pm 1.0088)$ & $-3.2902( \pm 0.6401)$ \\
\hline & $P D$ & - & - & - \\
\hline & $F A$ & - & - & - \\
\hline & GCL & $0.0196( \pm 0.0074)$ & - & - \\
\hline & $N G$ & & & $0.3179( \pm 0.1149)$ \\
\hline & CONSTANT & $-5.10803( \pm 1.8938)$ & $-3.9334( \pm 1.4008)$ & $0.0239( \pm 0.8846)$ \\
\hline \multirow[t]{3}{*}{ Statistics } & $\begin{array}{l}\mathrm{R}^{2} \\
\left(\text { Adj } \mathrm{R}^{2}\right)\end{array}$ & $\begin{array}{l}74.44 \\
(71.88)\end{array}$ & $\begin{array}{l}-50.92 \\
(48.11)\end{array}$ & $\begin{array}{l}54.92 \\
(52.16)\end{array}$ \\
\hline & F-Ratio & 29.13 & 18.15 & 19.90 \\
\hline & $P$-Value & $<0.0001$ & $<0.0001$ & $<0.0001$ \\
\hline
\end{tabular}


of the soils, different planting patterns and densities, different cropping techniques, different climate control management, nutrient management, and the incidence of pests and diseases. External factors than may affect productivity as well are the cultivation costs, the price of the products and state of the markets.

\section{Conclusions}

In this paper, an irrigation performance analysis was carried out in a greenhouse horticultural production area in the "Campo de Nijar" (Southern Spain). The aim of this study was to assess the productivity of the irrigation water and analyze possible limiting factors. Appropriate productivity performance indicators were calculated from data taken from a wide sample of crops in the area over the course of two different study periods.

Maximum marketable yields $(M Y)$ were achieved for relatively high $R I S$ values. This fact indicates that higher leaching fractions were required due to the high irrigation water salinity. Pear tomato was the crop that required the highest RIS value (1.45) to obtain a maximum yield while cherry tomato and watermelon required slightly lower values (approximately 1.30).

The overall productivity ratio $(C Y R)$, defined as the proportion of the potential yield expected under optimal conditions that has actually been attained, was $73.9 \%$ with a $17.5 \%$ coefficient of variation. The low values of the $C Y R$ value were somewhat expected considering irrigation water in this area has high salinity levels and relatively low irrigation average leaching fractions applied. The crop that showed the best productivity ratio was pear tomato with a $C Y R$ value of 0.77 .

The most productive crop was watermelon, which had a mean $C W P$ value of $23 \mathrm{~kg} / \mathrm{m}^{3}$. However, regarding the productivity of the crop in terms of economic income, the most efficient crop was cherry type tomato, with a $E W P$ value of approximately $15 € / \mathrm{m}^{3}$ due to its higher market price.

The better irrigation water quality observed in the second study period produced an increase of the crop productivity indices values for watermelon. However, the productivity of the tomato crops did not change significantly.

The influence of different factors was analyzed in this study. The type of crop, greenhouse technology level and agricultural season did not have a significant influence on the productivity indices.

The results of the study showed that the most significant variable affecting the productivity indices was the relative irrigation supply $(R I S)$ to the crop. Other variables that had an influence on the productivity were the length of the growing cycle in the case of tomato and the number of greenhouses per farm in the case of watermelon. The variability explained by these variables was $75 \%$ in the case of pear tomato, $50.5 \%$ in the case of cherry tomato and $55 \%$ in the case of watermelon. However, as a high percentage of the variability still remains unexplained, it can be concluded that other factors related to farmers' own management decisions affect crop yield and productivity. The experimental production functions (marketable yield versus relative irrigation supply) derived in this work can be useful to advise farmers on the optimum RIS values that maximize their expected marketable yields and economic returns.

Results of this work can be used to detect factors conditioning the irrigation management and can highlight possible weaknesses of the system. This is a primary step to suggest measures contributing to improve its productivity and sustainability. 
Acknowledgments The authors acknowledge the funding of the Spanish Ministry for Science and Innovation (contracts CTM2007-66639 and CGL2010-21865).

Open Access This article is distributed under the terms of the Creative Commons Attribution 4.0 International License (http://creativecommons.org/licenses/by/4.0/), which permits unrestricted use, distribution, and reproduction in any medium, provided you give appropriate credit to the original author(s) and the source, provide a link to the Creative Commons license, and indicate if changes were made.

\section{References}

Ahmad M, Kirby M, Islam M, Hossain MJ, Islam MM (2014) Groundwater use for irrigation and its productivity: status and opportunities for crop intensification for food security in Bangladesh. Water Resour Manag 28:1415-1429. doi:10.1007/s11269-014-0560-Z

Aldaya M, Martínez-Santos P, Llamas MR (2010) Incorporating the water footprint and virtual water into policy: reflections from the Mancha Occidental Region, Spain. Water Resour Manag 24:941-958. doi:10.1007/ s11269-009-9480-8

Ali M, Klein KK (2014) Water use efficiency and productivity of the irrigation districts in Southern Alberta. Water Resour Manag 28:2751-2766. doi:10.1007/s11269-014-0634-y

Allen RG, Pereira LS, Raes D, Smith M (1998) Crop evapotranspiration. Guidelines for computing crop water requirements. FAO Irrigation and Drainage Paper 56, FAO, Rome

Ayers RS, Westcot DW (1985) Water quality for agriculture. FAO Irrigation and Drainage Paper 29. FAO. Rome

Bonachela S, González AM, Fernández MD (2006) Irrigation scheduling of plastic greenhouse vegetable crops based on historical weather data. Irrig Sci 25(1):53-62. doi:10.1007/s00271-006-0034-Z

Bos MG, Murray-Rust DH, Merrey DJ, Johnson HG, Snellen WB (1994) Methodologies for assessing performance of irrigation and drainage management. Irrig Drain Syst 7(4):231-261. doi:10.1007/ BF00881553

Bralts VF, Edwards DM (1986) Field evaluation of drip irrigation submain units. Trans ASAE 29(6):1659-1664. doi:10.13031/2013.30369

Carreño J, Aguilar J, Moreno SM (2000) Gastos de agua y cosechas obtenidas en los cultivos protegidos del campo de Níjar (Almería). XIII Congreso Nacional de Riegos, Huelva

Clemens AJ (2006) Improving irrigated agriculture performance though an understanding of the water delivery process. Irrig Drain 55(3):223-234. doi:10.1002/ird.236

Córcoles J, de Juan J, Ortega J, Tarjuelo J, Moreno M (2012) Evaluation of irrigation systems by using benchmarking techniques. J Irrig Drain Eng ASCE 138(3):225-234. doi:10.1061/(ASCE)IR.1943-4774.0000386

Doorenbos J, Kassam AH (1979) Yield response to water. FAO Irrigation and Drainage Paper No. 33. Rome, FAO

Fernández MD, González AM, Carreño J, Pérez C, Bonachela S (2007) Analysis of on-farm irrigation performance in Mediterranean greenhouses. Agric Water Manag 89(3):251-260. doi:10.1016/j.agwat. 2007.02 .001

Hoekstra AY, Chapagain AK (2007) Water footprints of nations: water use by people as a function of their consumption pattern. Water Resour Manag 21:35-48. doi:10.1007/s11269-006-9039-x

Howell TA (2001) Enhancing water use efficiency in irrigated agriculture. Agron J 93(2):281-289. doi:10.2134/ agronj2001.932281x

Malano H, Burton M, Makin I (2004) Benchmarking performance in the irrigation and drainage sector: a tool for change. Irrig Drain 53(2):119-133. doi:10.1002/ird.126

Martínez J, Reca J (2014) Water use efficiency of surface drip irrigation versus an alternative subsurface drip irrigation method. J Irrig Drain Eng ASCE 140(10):04014030

Molden DJ, Sakthivadivel R (1999) Water accounting to assess use and productivity of water. J Water Resour Dev 15(1-2):55-71. doi:10.1080/07900629948934

Montesinos P, Camacho E, Campos B, Rodríguez-Díaz J (2011) Analysis of virtual irrigation water. Application to water resources management in a Mediterranean River Basin. Water Resour Manag 25:1635-1651. doi: 10.1007/s11269-010-9765-y

Orgaz F, Fernández MD, Bonachela S, Gallardo M, Fereres E (2005) Evapotranspiration of horticultural crops in an unheated plastic greenhouse. Agric Water Manag 72(2):81-96. doi:10.1016/j.agwat.2004.09.010

Pande VC, Sharda VN, Kurothe RS, Sena DR, Tiwari SP (2012) An empirical assessment of on-farm water productivity using groundwater in a semi-arid Indian watershed. Water Resour Manag 26:475-498. doi:10. 1007/s11269-011-9927-6 
Perry C (2007) Efficient irrigation; inefficient communication; Flawed recommendations. Irrig Drain 56:367378. doi:10.1002/ird.323

Reca J, García-Manzano A, Martínez J (2014) Optimal pumping scheduling for complex irrigation water distribution systems. J Water Resour Plan Manag 140(5):630-637. doi:10.1061/(ASCE)WR.1943-5452. 0000360

Rodríguez JA, Camacho E, López R (2004) Applying benchmarking and data envelopment analysis (DEA) techniques to irrigation districts in Spain. Irrig Drain 53(2):135-143. doi:10.1002/ird.128

Sánchez JA, Reca J, Martínez J (2015) Irrigation water management in a Mediterranean greenhouse district: irrigation adequacy assessment. Irrig Drain 64:299-313. doi:10.1002/ird.1908

Sanjuán JF (2007) Detección de la superficie invernada en la provincia de Almería a través de imágenes Raster. FIAPA, Almería

Statgraphics (2010) Statgraphics Centurion XVI, User Manual. Statpoint Technologies, Inc, Warrenton

Steduto P, Hsiao TC, Fereres E, Raes D (2012) Crop yield response to water. FAO Irrigation and Drainage paper 66. FAO. Rome

Su X, Li J, Singh V (2014) Optimal allocation of agricultural water resources based on virtual water subdivision in Shiyang River Basin. Water Resour Manag 28:2243-2257. doi:10.1007/s11269-014-0611-5

Thompson RB, Martínez-Gaitán C, Gallardo M, Giménez C, Fernández MD (2007) Identification of irrigation and $\mathrm{N}$ management practices that contribute to nitrate leaching loss from an intensive vegetable production system by use of a comprehensive survey. Agric Water Manag 89(3):261-274. doi:10.1016/j.agwat.2007.01.013

Valera DL, Belmonte LJ, Molina FD, López A (2014) Los invernaderos de Almería. Análisis de su tecnología y rentabilidad. Cajamar (ed.) Cátedra Cajamar de Economía y Agroalimentación de la Universidad de Almería (ed) Almería (Spain)

Wolters W (1992) Influences on the efficiency of irrigation water use. ILRI publication $\mathrm{n}^{\circ} 51$. International Institute for Land Reclamation and Improvement, Wageningen

Yihun Y, Haile A, Schultz B, Erkossa T (2013) Crop water productivity of irrigated teff in a water stressed region. Water Resour Manag 27:3115-3125. doi:10.1007/s11269-013-0336-x 